\title{
Evaluation of Bi-directional Causal Association Between Depression and Cardiovascular Diseases: A Mendelian Randomization study
}

Gloria Hoi-Yee Li, PhD ${ }^{1,2}$; Ching-Lung Cheung*, PhD ${ }^{1}$; Albert Kar-Kin Chung, FHKCPsych ${ }^{3}$; Bernard Man-Yung Cheung, FRCP ${ }^{4}$; Ian Chi-Kei Wong, PhD ${ }^{1,5}$; Marcella Lei-Yee Fok, MRCPsych ${ }^{6}$; Philip Chun-Ming Au, MPhil ${ }^{1}$; Pak-Chung Sham, $\mathrm{PhD}^{1,3}$

${ }^{1}$ Department of Pharmacology and Pharmacy, Li Ka Shing Faculty of Medicine, The University of Hong Kong, Hong Kong. ${ }^{2}$ Department of Health Technology and Informatics, The Hong Kong Polytechnic University, Hong Kong. ${ }^{3}$ Department of Psychiatry, Li Ka Shing Faculty of Medicine, The University of Hong Kong, Hong Kong. ${ }^{4}$ Department of Medicine, Li Ka Shing Faculty of Medicine, The University of Hong Kong, Hong Kong. ${ }^{5}$ Research Department of Practice and Policy, School of Pharmacy, University College London, London, UK. ${ }^{6}$ Department of Health Service and Population Research, Institute of Psychiatry, Psychology \& Neuroscience, King's College London, London, UK.

\section{Correspondence and reprint requests:}

Ching-Lung Cheung, PhD, Department of Pharmacology and Pharmacy, The University of Hong Kong, Pokfulam, HONG KONG

Email : lung1212@hku.hk; Tel: +852-2831-5085 Fax: +852-2816-2095

\author{
Funding: N/A
}

Word Count: 4455 


\section{Abstract}

\section{Background}

Depression and cardiovascular disease (CVD) are associated with each other but their relationship remains unclear. We aim to determine whether genetic predisposition to depression are causally linked to CVD [including coronary artery disease (CAD), myocardial infarction (MI), stroke and atrial fibrillation (AF)].

\section{Methods}

Using summary statistics from the largest genome-wide association studies (GWAS) or GWAS meta-analysis of depression (primary analysis: $n=500,199$ ), broad depression (help-seeking behavior for problems with nerves, anxiety, tension or depression; secondary analysis: $n=322,580), \operatorname{CAD}(n=184,305), \operatorname{MI}(n=171,875)$, stroke $(n=446,696)$ and $\operatorname{AF}(n=1,030,836)$, genetic correlation was tested between two depression phenotypes and CVD [MI, stroke and AF (not CAD as its correlation was previously confirmed)]. Causality was inferred between correlated traits by Mendelian Randomization analyses.

\section{Results}

Both depression phenotypes were genetically correlated with MI (depression: $\mathrm{r}_{\mathrm{G}}=0.169 ; \mathrm{P}=9.03 \times 10^{-9} ;$ broad depression: $\mathrm{r}_{\mathrm{G}}=0.123 ; \mathrm{P}=1 \times 10^{-4}$ ) and $\mathrm{AF}$ (depression: $\mathrm{r}_{\mathrm{G}}=0.112 ; \mathrm{P}=7.80 \times 10^{-6} ;$ broad depression: $\left.\mathrm{r}_{\mathrm{G}}=0.126 ; \mathrm{P}=3.62 \times 10^{-6}\right)$. Genetically doubling the odds of depression was causally associated with increased risk of CAD (OR=1.099; 95\% CI:1.031-1.170; $\mathrm{P}=0.004)$ and $\mathrm{MI}\left(\mathrm{OR}=1.146 ; 95 \% \mathrm{CI}: 1.070-1.228 ; \mathrm{P}=1.05 \times 10^{-4}\right)$. Adjustment for blood lipid levels/smoking status attenuated the causality between depression and CAD/MI. Null causal association was observed for CVD on depression. Similar pattern of results was observed in the secondary analysis for broad depression.

\section{Conclusions}


Genetic predisposition to depression may have positive causal roles on CAD/MI. Genetic susceptibility to self-awareness of mood problems may be a strong causal risk factor of CAD/MI. Blood lipid levels and smoking may potentially mediate the causal pathway. Prevention and early diagnosis of depression are important in management of CAD/MI. 


\section{Introduction}

Depressive disorder was ranked the third leading cause of non-fatal health loss in the Global Burden of Disease Study 2017 (GBD 2017 Disease and Injury Incidence and Prevalence Collaborators, 2018). As reported by the World Health Organization, more than 300 million people were suffering from depression in 2017 (World Health Organization, 2017). Among patients with depression, cardiovascular diseases (CVD) often co-exist. Observational studies and meta-analyses demonstrated that depression and CVD [including coronary artery disease (CAD) (Gan et al., 2014), myocardial infarction (MI) (Gan et al., 2014), stroke (Barlinn et al., 2015) and atrial fibrillation (AF) (Garg et al., 2019, Goren et al., 2013)] were associated with each other, and the relationship was bi-directional (Lippi et al., 2009). Nevertheless, there is insufficient evidence on whether depression causally leads to various CVD traits, or vice versa. Emerging reports also called for clinical awareness on the interplay between stress-related psychiatric disorders and CVD (Bacon, 2019, Song et al., 2019). Given the high prevalence of the diseases and the huge public health impact incurred, it is important to understand the relationship between depression and CVD although stress is just one of the risk factors for depression.

Published genome-wide association studies (GWAS) have adopted different depression phenotypes, ranging from self-declared depression-related phenotypes to clinical diagnosis of major depressive disorder (MDD). As accumulating evidence suggested that genetic association results obtained from the combination of carefully curated research cohorts with self-declared depression cohorts are applicable to clinical MDD (Wray et al., 2018), increasing number of studies are using this approach. Recently, Howard et al 
conducted a GWAS meta-analysis of depression with 807,553 individuals (246,363 cases; 561,190 controls) (Howard et al., 2019) from the three largest studies of different depression phenotypes, including self-reported clinical diagnosis or treatment of depression in 23andMe participants (75,607 cases and 231,747 controls) (Hyde et al., 2016), self-reported diagnosis together with conventional methods like structured diagnostic interviews in participants of Psychiatric Genomics Consortium (PGC) $(43,204$ cases and 95,680 controls) (Wray et al., 2018), and broad depression, which was defined as "self-reported past help-seeking via a general practitioner or psychiatrist for problems with nerves, anxiety, tension or depression" in UK Biobank participants (127,552 cases and 233,763 controls) (Howard et al., 2018). The availability of GWAS data enables the conduct of Mendelian randomization (MR) analysis, which is considered a powerful approach making use of genetic variation as random experiment to evaluate the causal association between two traits or diseases, when such relationships cannot be directly evaluated using clinical trials (Davies et al., 2018). Its principles were described clinically elsewhere (Davies et al., 2018). In brief, genetic variants that influence the susceptibility to a disease/trait (like depression as exposure) could serve as instruments and determine the association of lifelong risk of another disease/trait (like CAD as outcome). The randomly assigned genetic variants utilized in MR analyses were fixed at conception, making MR findings less likely to be influenced by unmeasured confounding and reverse causation when compared to observational studies (Davies et al., 2018), relying on several assumptions (Figure 1). In this study, we adopted a bi-directional two-sample MR approach to infer causality between genetically determined depression and several types of CVD after confirming genetic correlation exists between the traits (Figure 1). We also aim to identify the potential mediators in the causal pathway. 


\section{Methods}

Data sources

The meta-analysis of depression conducted by Howard et al (2019) included the three largest GWAS using different depression phenotypes in participants from 23andMe, PGC and UK Biobank (Howard et al., 2019). Notably, the summary statistics of all genetic variants in the study by Howard et al were only publicly available in the form of metaanalysis of PGC and UK Biobank studies without samples from 23andMe, comprising 170,756 cases and 329,443 controls. Taking into account the GWAS sample size of different depression phenotypes, the primary analyses in the current study examines the relationship between depression and various CVD, with depression defined by the metaanalysis of PGC (self-reported diagnosis together with conventional identification methods) and UK Biobank (broad depression) studies comprising 500,199 individuals. Meanwhile, the broad depression dataset is a subset of the GWAS meta-analysis of depression conducted by Howard et al (2019). Due to its relatively small sample size, only 14 SNPs reached genome-wide significance, limiting the number of genetic instruments employed in MR analyses. In view of the anticipated low power, MR analyses evaluating the causal association between broad depression and CVD were included as secondary analyses.

In evaluating the genetic correlation/causal association between depression phenotypes and various CVD, summary statistics of genetic instruments were extracted from the 
largest possible publicly available GWAS/GWAS meta-analysis. Out of the 15 GWAS datasets from which summary statistics were extracted, 13 of the GWAS were conducted in Europeans only, while two GWAS comprised approximately $80 \%$ participants of European ancestry. Biases of the causal estimates may arise due to sample overlap. If both the case and control participants in the outcome dataset are also in the exposure dataset, the extent of bias is a linear function of the proportion of overlap between the exposure and outcome datasets (Burgess et al., 2016). Therefore, GWAS datasets with minimal chance of sample overlap were chosen. For example, there was a published GWAS metaanalysis of CAD comprising UK Biobank participants, with a larger sample size but possible sample overlap with depression datasets. To avoid any possible biases due to sample overlap, we conducted the MR analyses using a smaller CAD dataset without UK Biobank participants.

On the other hand, depression is reported to be associated with several risk factors of CVD, including blood pressure (Lewington et al., 2002, Sparrenberger et al., 2009), levels of blood lipid [low-density lipoprotein cholesterol (LDL-C), high-density lipoprotein cholesterol (HDL-C) and triglycerides)] (Enko et al., 2018, Welty, 2013), body mass index (BMI) (Khan et al., 2018, Luppino et al., 2010), type-2 diabetes (Kannel et al., 1979, Vancampfort et al., 2015), inflammatory markers [levels of interleukin-6 (IL-6) and Creactive protein (CRP) (Pepys et al., 2003) as proxies of systemic inflammation] (Howren et al., 2009, Libby, 2006), physical activity (in terms of average acceleration measured by wrist-worn accelerometer) (Kamphuis et al., 2007), smoking status (Ambrose et al., 2004, Wootton et al., 2018) and insomnia (Larsson et al., 2019, Nutt et al., 2008). 
However, it remains unknown if these risk factors mediate the association between depression and CVD, or depression itself is an independent risk factor (Carney et al., 2017). By multivariable MR approach (Burgess et al., 2017, Burgess et al., 2015), we examine if such risk factors may potentially mediate the association between depression and CVD. Data sources of exposures, potential mediators and outcomes are listed in Supplementary Table S1.

\section{Estimation of genetic correlation}

Using genome-wide summary statistics, linkage disequilibrium (LD) score regression (LDSC) (Bulik-Sullivan et al., 2015a, Bulik-Sullivan et al., 2015b) was employed to estimate the genetic correlation between two depression phenotypes and various CVD (including MI, stroke and AF but not CAD which was evaluated in the original GWAS (Howard et al., 2019, Howard et al., 2018)). As these complex diseases were affected by thousands of genetic variants with small effect size, utilizing genome-wide data in genetic correlation analyses might provide more information regarding their genetic etiology than using only the significantly associated SNPs in MR studies, which also depend on the statistical power of respective GWAS. Therefore, LCSD was firstly employed to unravel genetic correlation between diseases, providing insights on shared genetic ethology between diseases. The results of genetic correlation analyses subsequently help to prioritize the identification of likely causal relationships (Bulik-Sullivan et al., 2015a). Pre-computed LD scores suitable for European-ancestry samples and Python command line tool were used. 
Selection of genetic instruments for MR analyses

Causal association was tested between genetically correlated depression/broad depression and CVD trait pairs. The genetic instruments adopted in univariable and multivariable MR analyses for each exposure-outcome pair are the same, and they satisfied the MR assumptions (Figure 1). Briefly, independent GWAS-derived exposure-associated genetic variants, which were not in LD with each other, were initially selected as the genetic instruments to represent genetic predisposition to the exposure trait. The summary statistics of these initial genetic instruments were retrieved from the datasets of outcome and potential mediators. If an initial genetic instrument was unavailable in the GWAS of outcome or potential mediator datasets, a proxy variant in high $\operatorname{LD}\left(\mathrm{r}^{2}>0.8\right)$ and present in all the exposure, outcome and potential mediator datasets was selected as the genetic instrument to replace the initial one. If no proxies could be identified, the genetic instrument was excluded from MR analysis. One of the MR assumptions is that the genetic instruments only act on the outcome via the exposure and/or potential mediators (Figure 1). Violation of this assumption is known as horizontal pleiotropy. Pleiotropic genetic instruments associated with the outcome through pathways other than the exposure/mediators under investigation were excluded from MR analyses. Such genetic variants were defined as those with genome-wide significant association with alternative pathways in GWAS conducted by representative consortiums, as revealed by the webinterfaced PhenoScanner (Staley et al., 2016), a curated database of publicly available GWAS. If MR pleiotropy residual sum and outlier (MR-PRESSO) identified outliers, the MR analyses were repeated after exclusion of the outliers. Genetic instruments selected by the above procedures constituted the main analysis. As a sensitivity analysis, the MR analysis was repeated after excluding the genetic instruments which did not reach 
genome-wide significance in the exposure dataset (such as proxies). Detailed selection of genetic instruments is elaborated in Supplementary Methods 1. The number of genetic instruments, and summary statistics applied in each MR analysis are included in Table 1 and Supplementary Tables S2-S13 respectively.

\section{Power calculation}

Proportion of variance in the exposure explained by the genetic instruments was derived from the Mangrove package (Jostins, 2017) in R, which also takes into account the disease prevalence. An online web tool, mRnd (http://cnsgenomics.com/shiny/mRnd/) (Brion et al., 2013), was employed to perform power calculation. Strength of genetic instruments for each MR analysis are presented in Table 1. For each pair of causal relationship under investigation, a plot of power against odds ratio of the true underlying association is shown in Supplementary Figure S1.

\section{MR analyses}

All the genetic instruments were oriented such that the effect alleles were positively associated with the exposure. The effect alleles were matched across the summary data of the exposure, potential mediator and outcome dataset. Due to the unavailability of effect allele frequency of some GWAS datasets, allele frequencies were not used to align palindromic genetic instruments on ambiguous strands across different datasets. Nonpalindromic proxies in high $\operatorname{LD}\left(\mathrm{r}^{2} \geq 0.8\right)$ were identified for the palindromic instruments (Hartwig et al., 2016). Univariable inverse-variance weighted (IVW) method was used 
for main MR analysis to assess the total effect of the exposure on the outcome (Burgess et al., 2013, Burgess et al., 2017). Weighted median method (Bowden et al., 2016) was employed as a sensitivity analysis. MR-Egger intercept test (Bowden et al., 2015) and global test of MR-PRESSO (Verbanck et al., 2018) were employed to detect for the presence of pleiotropy. In case univariable MR analysis suggested the presence of causal association, multivariable IVW analysis was also performed to dissect the mechanisms in the causal pathway from the risk factor to the outcome (Burgess et al., 2017, Burgess and Thompson, 2015). It was reported that the causal estimates derived from univariable MR analysis represents the total effect of the exposure on the outcome. Multivariable MR analysis can be used to estimate the direct causal effect of the exposure on the outcome by keeping the potential mediator constant. Presence of difference between the causal estimates of the univariable (total effect) and multivariable MR analysis (direct causal effect) implies that causal effect acts at least in part via the potential mediator (indirect effect) (Burgess et al., 2017). Multivariable MR-Egger intercept test was applied to detect for presence of residual pleiotropy via other unmeasured risk factors (Rees et al., 2017). Different methods of MR analyses are described in Supplementary Methods 2.

As the exposures in all the MR analyses are binary variables, the causal estimates were initially equivalent to the change in the outcome per unit change in the exposure on the $\log$ odds scale [=exponential 1, i.e. 2.72-fold change in the odds of the exposure]. For the sake of interpretation, the causal estimates were converted by multiplying $0.693(=\ln 2)$ and then exponentiating to represent change in outcome per 2-fold change in the prevalence of the exposure (Burgess et al., 2018). 


\section{Results}

\section{Genetic correlation}

Genetic correlation between the depression phenotypes and various CVD are shown in Table 2. Depression had strong and positive genetic correlation with broad depression $\left(r_{G}=0.9732 ; \mathrm{SE}=0.0041 ; \mathrm{P}=0\right)$. Positive significant genetic correlation was observed for both depression phenotypes with $\mathrm{MI}$ (depression: $\mathrm{r}_{\mathrm{G}}=0.1688 ; \mathrm{SE}=0.0294 ; \mathrm{P}=9.03 \times 10^{-9}$; broad depression: $\mathrm{r}_{\mathrm{G}}=0.1231 ; \mathrm{SE}=0.0324 ; \mathrm{P}=1 \times 10^{-4}$ ) and $\mathrm{AF}$ (depression: $\mathrm{r}_{\mathrm{G}}=0.1124$; $\mathrm{SE}=0.0251 ; \mathrm{P}=7.80 \times 10^{-6} ;$ broad depression: $\left.\mathrm{r}_{\mathrm{G}}=0.1258 ; \mathrm{SE}=0.0272 ; \mathrm{P}=3.62 \times 10^{-6}\right)$, but not with stroke. In addition to CAD which was demonstrated to be genetically correlated with depression phenotypes (Howard et al., 2019, Howard et al., 2018), bi-directional two-sample MR was conducted for six pairs of traits (two depression phenotypes versus CAD, MI and AF).

Two-sample MR of depression and CVD

To account for multiple testing, we applied a conservative Bonferroni corrected threshold $\left(\alpha=4.167 \times 10^{-3}=0.05 / 12\right)$ in the subsequent two-sample bi-directional MR analyses. The primary analysis aims to evaluate the causal relationship between depression and various types of CVD. With 93 genetic instruments in the main analysis, univariable IVW method demonstrated that genetically doubling the odds of depression increased the risk of CAD and MI by $9.9 \%$ and $14.6 \%$ respectively (CAD: OR=1.099; 95\% CI:1.031-1.170; MI: $\mathrm{OR}=1.146 ; 95 \% \mathrm{CI}: 1.070-1.228$ ) (Figure 2a; Supplementary Figures S2a and S3a). 
Sensitivity analysis of weighted median method yielded similar estimates (CAD: $\mathrm{OR}=1.138 ; 95 \% \mathrm{CI}: 1.042-1.242 ; \mathrm{MI}: \mathrm{OR}=1.163 ; 95 \% \mathrm{CI}: 1.057-1.281)$. The association remained significant after corrected for multiple testing. In multivariable IVW analysis adjusting for beta estimates of smoking status, the causal association between depression and $\mathrm{CAD} / \mathrm{MI}$ were attenuated $(\mathrm{CAD}: \mathrm{OR}=1.027 ; 95 \% \mathrm{CI}: 0.956-1.103$; $\mathrm{MI}: \mathrm{OR}=1.053$; 95\% CI: 0.975-1.139). With adjustment for blood lipid levels, the causal association was also attenuated between depression and CAD (OR=1.060; 95\% CI: 0.994-1.130), but not for MI. There was little change in causal estimate after adjustment for other potential mediators (Figure 2b). MR-Egger intercept tests were insignificant in all univariable and multivariable MR analyses of depression on both $\mathrm{CAD}$ and $\mathrm{MI}(\mathrm{P}>0.05)$ (Figures $2 \mathrm{a}$ and 2b). MR-PRESSO global tests did not detect any horizontal pleiotropy $(\mathrm{P}>0.05)$ (Figure 2a).

In the sensitivity analyses, genetic instruments which no longer attained genome-wide significance in the depression dataset were excluded. The same pattern of results was observed. With 34 genetic instruments, univariable IVW analysis showed that genetic predisposition to increased risk of depression was causally linked to increased risk of CAD and MI (CAD: OR=1.103; 95\% CI: 1.014-1.199; MI: OR=1.180; 95\% CI: $1.068-$ 1.303). Similar causal estimates were obtained from the weighted median method (CAD: $\mathrm{OR}=1.131 ; 95 \% \mathrm{CI}: 1.004-1.274 ; \mathrm{MI}: \mathrm{OR}=1.162 ; 95 \% \mathrm{CI}: 1.014-1.331)$ (Figure 3a; Supplementary Figures S2b and S3b). In multivariable MR analysis, the causal association of depression with both CAD and MI was attenuated after adjustment for beta estimates of smoking status (CAD: $\mathrm{OR}=1.030 ; 95 \% \mathrm{CI}$ : 0.931-1.138; $\mathrm{MI}$ : $\mathrm{OR}=1.085$; 
95\% CI: 0.971-1.213) (Figure 3b). In addition, the causal association between depression and $\mathrm{CAD}$ was also attenuated when adjusted for blood lipid levels (OR=1.041; 95\% CI: 0.948-1.143), type 2 diabetes $(\mathrm{OR}=1.083 ; 95 \% \mathrm{CI}$ : 0.994-1.180), $\mathrm{BMI}(\mathrm{OR}=1.079 ; 95 \%$ CI: $0.992-1.175)$ and blood pressure (OR=1.086; 95\% CI: 0.996-1.183) in multivariable MR analyses. MR-PRESSO global tests, as well as MR-Egger intercept tests in both univariable and multivariable $\mathrm{MR}$ analyses were insignificant $(\mathrm{P}>0.05)$, indicating the absence of horizontal pleiotropy.

Using 93 genetic instruments in the main analysis, univariable IVW analyses showed null causal association between depression and AF (Figure 2a). While MR-Egger intercept test suggested no evidence of pleiotropy, MR-PRESSO suggested three horizontal pleiotropy outliers were present. Consistent null causal association was observed after excluding the outliers with the use of 90 instruments (Figure 2a, Supplementary Figure S4). MR-PRESSO global test was still statistically significant $(\mathrm{P}=0.002)$, implying that overall horizontal pleiotropy might be present. However, MR-PRESSO did not identify any significant outliers of horizontal pleiotropy. In sensitivity analysis including only 34 instruments reaching genome-wide significance in the meta-analysis of depression, there was null causal association between depression and AF in the univariable analysis. Insignificant MR Egger intercept and MR-PRESSO global tests implied the absence of horizontal pleiotropy (Figure 3a; Supplementary Figure S4b). 
We found no evidence of causal effects of any CVD on depression (Supplementary Table S14a and Supplementary Figures S5-S7). MR-Egger intercept and MR-PRESSO global tests did not detect any horizontal pleiotropy outliers.

In the secondary analysis evaluating the causal relationship between broad depression and various CVD, similar pattern of results was obtained. Results of the secondary analysis were detailed in Supplementary Text 1, Supplementary Figures S8-S15.

\section{Discussion}

In this study, we demonstrate the presence of genetic correlation between depression and MI, as well as AF. The primary two-sample MR analysis provides evidence that genetically increasing odds of depression are causally associated with increased risk of CAD and MI. We found no evidence on the presence of causal relationship between depression and AF. Reverse causation of CVD on depression is not detected. Same pattern of results was observed in the secondary analysis which assesses the causal relationship between broad depression (as a subset of depression) and CVD. We also investigated if any potential mediator plays a role in the causal pathway from depression to CVD.

Our LDSC analysis revealed that depression and broad depression were strongly correlated with each other. Positive genetic correlation was present between both depression phenotypes and MI, as well as AF. Genetic correlation was also reported between depression and CAD (Howard et al., 2019, Howard et al., 2018), suggesting 
these traits may have shared genetic etiology. Stroke was the only tested CVD trait which did not have genetic correlation with both depression phenotypes. As causal association was less likely in the absence of genetic correlation, subsequent MR analysis was not performed in the current study. In line with this, a two-sample MR analysis did not support the presence of causal relationship between genetically determined risk of depression on ischemic stroke (Gill et al., 2019).

We inferred causality of depression on various CVD by MR approach as our primary analysis. Univariable IVW analysis using 93 genetic instruments showed that genetically doubling the odds of depression increased the risk of CAD and MI by $9.9 \%(\mathrm{OR}=1.099)$ and $14.6 \%$ (OR: 1.146), respectively. The causal association remained significant after corrected for multiple testing. Similar causal estimates were obtained in the sensitivity analysis using 34 genetic instruments. These are consistent with the previous metaanalysis of population-/community-based prospective cohort studies (Gan et al., 2014). Results from MR-Egger intercept and MR-PRESSO global tests implied that horizontal pleiotropy is unlikely. The current study provides robust evidence on the causality of depression on CAD and MI. Similar pattern of results was observed in the secondary analysis evaluating the causal effects of broad depression on CAD and MI.

Depression and CVD are hypothesized to be linked by several biological (inflammatory processes, dysfunction in the autonomic nervous system, endothelial and platelet dysfunction) and behavioral mechanisms (physical exercise, medical treatment and smoking) (Carney and Freedland, 2017). We evaluated some of the above mechanisms 
using multivariable MR analyses. The attenuation of causal effect of genetically determined depression on $\mathrm{CAD} / \mathrm{MI}$ after adjustment for smoking status suggested that smoking status might potentially mediate the causality. Patients with depression may smoke as "self-medication" to alleviate symptoms of the illness or side-effects of medications (Wootton et al., 2018) but toxic components of cigarettes might increase the incidence of CAD and MI by inflammation, thrombosis or increase in oxidative stress (Ambrose and Barua, 2004). On the other hand, multivariable MR analysis adjusted for blood lipid levels (LDL-C, HDL-C and triglycerides) attenuated the causality between depression and CAD. Blood lipid level patients with MDD were reported to have lower HDL-C, higher triglycerides (Enko et al., 2018) and LDL-C (Parekh et al., 2017) levels in serum. One possible explanation for such lipid profile could be life-style related factors (Enko et al., 2018), such as sedentary behaviors and poor adherence to physical exercises and diet (e.g. eating comfort food rich in fats and sugar to improve mood (Atlantis et al., 2011)) for patients with depression (Carney and Freedland, 2017). Meanwhile, a combination of low HDL-C, high LDL-C and triglyceride levels are well-known risk factors of atherosclerosis (Welty, 2013), and thus increasing the risk of CAD. For broad depression, the causal association with CAD was attenuated after adjusting for blood lipid levels, type 2 diabetes, BMI, blood pressure and smoking status in multivariable MR analysis, indicating that causality might be partly mediated by these factors. This is further discussed in Supplementary Text 1. Due to the difference in definitions (detailed in Supplementary Text 2), slightly different results of MR analyses of depression and broad depression on CAD/MI were observed in the present study, which is discussed in Supplementary Text 3. A few published MR studies also investigated the causality 
between depression and CVD traits. Comparison with these studies is further discussed in Supplementary Text 4.

There are several clinical implications. Our research findings suggest that genetic predisposition to depression is a causal risk factor of CAD and MI, leading to the hypothesis that alleviation in depression might reduce the risk of CAD and MI. Although a few RCTs demonstrated that antidepressant therapy improved depression but had no effect on cardiac outcomes (Berkman et al., 2003, Zuidersma et al., 2013), such null effect might be because the antidepressant intervention on depression was weak and short-term that did not pose much effect on the long-term cardiac outcome (Shapiro, 2013). In addition, some depression-related medications would result in arrhythmias (Girardin et al., 2013), weight gain (Gafoor et al., 2018) and type 2 diabetes (Galling et al., 2016), which are known risk factors of CVD (Girardin et al., 2013). The robust causal association between depression and CAD / MI strengthens the idea that prevention and early diagnosis of depression or related mood disorder may help preventing CVD. Moreover, the depression definition adopted in this study is a mix of self-reported diagnosis together with conventional methods like structured diagnostic interviews, as well as broad depression, which represents self-awareness of mood problems (a stage preceding and not necessarily clinical diagnosis of depression), and a proxy phenotype of stress. In a recent population-based, sibling controlled cohort study comprising 136,637 patients with stress-related disorders, the crude incidence rate of any CVD in these patients were higher than their unaffected siblings and matched unexposed individuals from the general population (Song et al., 2019). A meta-analysis of 46 cohorts with 
$2,017,276$ participants $(222,253$ with anxiety disorder) revealed that anxiety was associated with an elevated risk of coronary heart disease, heart failure, but not AF (Emdin et al., 2016). The findings of our study may partly explain the comorbidity of stress-related and anxiety disorders with CVD. Given the potential mediating roles of smoking and blood lipid levels in the causal pathway of depression to CVD, appropriate stress management strategies with change of lifestyle-related factors (such as smoking cessation and intake of less comfort foods of high energy) may be warranted to prevent CVD in patients with depression, stress-related or anxiety disorders.

The current study has several strengths. MR approach is applied to infer causality between two diseases, which is infeasible by RCT, as it is unethical to leave the patients with one disease untreated with the aim to observe the occurrence of another disease outcome. Two-sample MR approach is reported to have increased statistical power particularly for testing causality on binary disease outcomes (Lawlor, 2016). Genetic instruments adopted in this study were selected from the largest possible and well-powered GWAS studies. Hence, the current study is well-powered (Supplementary Figure S1). The relatively high F-statistic $(\geq 1523.43)$ of the genetic instruments involved in the main primary MR analyses of depression implied a lower chance of weak instrument bias. Although the genetic instruments employed in the MR analyses of broad depression (Table 1) were relatively weak, this should have causal estimates biased towards the null in two-sample MR analysis (Pierce et al., 2013). The causality inferred for broad depression is thus unlikely to be false positive. 
This study also has limitations. Firstly, functions of the genetic instruments and how they influence the risk factors were not fully understood. Although we intended to be stringent in identifying pleiotropic instruments based on the information available in PhenoScanner in order to exclude genetic instruments likely to have horizontal pleiotropy with the outcome, it is possible that the genetic instruments may have an indirect effect on the outcome via a currently unknown pathway that does not involve the risk factor of interest. Nevertheless, we addressed this issue by adopting MR-Egger intercept and MR-PRESSO tests, though it cannot be ruled out unequivocally. Secondly, we attempted to reveal the potential mediators in the causal pathway from depression to CVD by multivariable MR analysis. However, we acknowledged that the list of potential mediators being examined may not be exhaustive and future studies on additional potential mediators are warranted. Thirdly, two out of the 15 GWAS datasets from which the summary statistics were extracted from comprised predominantly Europeans (approximately 80\%). Population stratification may confound the association between depression and various CVD, violating one of the MR assumptions. Nevertheless, adjustments for principal components were performed in the respective GWAS (Hoffmann et al., 2017, Nikpay et al., 2015), alleviating the potential effects of population stratification on the MR findings. Fourthly, we intended to explore the potential mediator in the causal pathway from depression to CVD by multivariable MR analysis. Yet, the sample size of GWAS of the two inflammation markers, CRP (n=9,961) (Prins et al., 2017) and IL-6 $(n=8,293)$ (AholaOlli et al., 2017), were small. The roles of various inflammatory markers in the causal pathway may be examined again when summary statistics from larger GWAS become available. Fifthly, study participants included in the depression meta-analysis were not screened for CVD at baseline, and vice versa. The presence of outcome in the exposure 
dataset may inflate the causal estimates in MR analyses. However, this is a general limitation of two-sample MR analyses and is inevitable without individual-level data. Sixthly, non-overlapping samples were utilized in the exposure and outcome datasets as far as possible to avoid bias. However, due to the unavailability of the raw genetic data, we could not determine the proportion of sample overlap between exposure and outcome datasets.

In conclusion, genetic predisposition to depression is causally associated with CAD and MI, but reverse causation is not observed. Genetic susceptibility to increased selfawareness of mood problems, preceding and not necessarily clinical diagnosis of depression, may be a strong causal risk factor of CAD and MI. The causal association contributes to the shared comorbidity of depression and CAD/MI. 
Author Contributions: GHL and CLC had full access to all the data in the study and take responsibility for the integrity of the data and the accuracy of the data analysis. GHL and CLC designed the study and wrote the first draft of the manuscript. GHL, CLC, AKC, BMC, ICW, MLF, PCA and PCS interpreted, critically evaluated, and improved the study design and manuscript, and shared the responsibility for the final manuscript and the decision to submit. GHL and CLC are responsible for data collection and evaluation, and approval of the manuscript.

Conflicts of interest: The authors declare no conflict of interest. 
Table 1. Power calculation of MR analysis for depression phenotypes and various CVD

\begin{tabular}{|c|c|c|c|c|c|c|c|c|}
\hline & \multicolumn{2}{|c|}{ Exposure } & \multicolumn{2}{|c|}{ Outcome } & \multirow{2}{*}{$\begin{array}{l}\text { Primary / } \\
\text { Secondary / } \\
\text { Sensitivity } \\
\text { analysis? }\end{array}$} & \multirow[b]{2}{*}{$\begin{array}{l}\text { Number of genetic } \\
\text { instruments included } \\
\text { in MR analysis } \\
\text { (Total number of } \\
\text { independent genetic } \\
\text { variants identified in } \\
\text { GWAS - number of } \\
\text { genetic variants } \\
\text { excluded due to lack of } \\
\text { proxies - number of } \\
\text { pleiotropic variants) }\end{array}$} & \multirow[b]{2}{*}{$\begin{array}{l}\text { Proportion } \\
\text { of variance } \\
\text { explained by } \\
\text { the genetic } \\
\text { instruments } \\
\text { on exposure } \\
(\%)\end{array}$} & \multirow[b]{2}{*}{ F-statistics } \\
\hline & Disease & Sample size & Disease & Sample size & & & & \\
\hline \multirow[b]{2}{*}{1} & \multirow[b]{2}{*}{ Depression } & \multirow{2}{*}{$\begin{array}{l}\text { Total: } 500,199 ; \\
\text { Cases: } 170,756 ; \\
\text { Controls: } 329,443\end{array}$} & \multirow{2}{*}{$\begin{array}{l}\text { Coronary } \\
\text { artery disease }\end{array}$} & \multirow{2}{*}{$\begin{array}{l}\text { Total: } 184,305 ; \\
\text { Cases: } 60,801 ; \\
\text { Controls: } 123,504\end{array}$} & Primary analysis & $93(102-2-7)$ & 0.878 & 1633.53 \\
\hline & & & & & $\begin{array}{l}\text { Sensitivity } \\
\text { analysis }\end{array}$ & 34 & 0.439 & 813.67 \\
\hline \multirow[b]{2}{*}{2} & \multirow{2}{*}{ Depression } & \multirow{2}{*}{$\begin{array}{l}\text { Total: 500,199; } \\
\text { Cases: } 170,756 ; \\
\text { Controls: } 329,443\end{array}$} & \multirow{2}{*}{$\begin{array}{l}\text { Myocardial } \\
\text { infarction }\end{array}$} & \multirow{2}{*}{$\begin{array}{l}\text { Total: } 171,875 ; \\
\text { Cases: } 43,676 ; \\
\text { Controls: } 128,199\end{array}$} & Primary analysis & $93(102-2-7)$ & 0.878 & 1523.43 \\
\hline & & & & & $\begin{array}{l}\text { Sensitivity } \\
\text { analysis }\end{array}$ & 34 & 0.439 & 758.86 \\
\hline \multirow[b]{2}{*}{3} & \multirow[b]{2}{*}{ Depression } & \multirow{2}{*}{$\begin{array}{l}\text { Total: } 500,199 ; \\
\text { Cases: } 170,756 ; \\
\text { Controls: } 329,443\end{array}$} & \multirow{2}{*}{$\begin{array}{l}\text { Atrial } \\
\text { fibrillation }\end{array}$} & \multirow{2}{*}{$\begin{array}{l}\text { Total: } 1,030,836 ; \\
\text { Cases: } 60,620 ; \\
\text { Controls: } 970,216\end{array}$} & Primary analysis & $93(102-2-7)$ & 0.878 & 9131.91 \\
\hline & & & & & $\begin{array}{l}\text { Sensitivity } \\
\text { analysis }\end{array}$ & 34 & 0.439 & 4546.32 \\
\hline 4 & $\begin{array}{l}\text { Coronary artery } \\
\text { disease }\end{array}$ & $\begin{array}{lr}\text { Total: } & 184,305 \\
\text { Cases: } & 60,801 ; \\
\text { Controls: } & 123,504\end{array}$ & Depression & $\begin{array}{l}\text { Total: 500,199; } \\
\text { Cases: } 170,756 ; \\
\text { Controls: } 329,443\end{array}$ & Primary analysis & $47(63-6-10)$ & 4.281 & 22372.23 \\
\hline
\end{tabular}




\begin{tabular}{|c|c|c|c|c|c|c|c|c|}
\hline & \multicolumn{2}{|c|}{ Exposure } & \multicolumn{2}{|c|}{ Outcome } & \multirow{2}{*}{$\begin{array}{l}\text { Primary / } \\
\text { Secondary / } \\
\text { Sensitivity } \\
\text { analysis? }\end{array}$} & \multirow[b]{2}{*}{$\begin{array}{l}\text { Number of genetic } \\
\text { instruments included } \\
\text { in MR analysis } \\
\text { (Total number of } \\
\text { independent genetic } \\
\text { variants identified in } \\
\text { GWAS - number of } \\
\text { genetic variants } \\
\text { excluded due to lack of } \\
\text { proxies - number of } \\
\text { pleiotropic variants) }\end{array}$} & \multirow[b]{2}{*}{$\begin{array}{l}\text { Proportion } \\
\text { of variance } \\
\text { explained by } \\
\text { the genetic } \\
\text { instruments } \\
\text { on exposure } \\
(\%)\end{array}$} & \multirow[b]{2}{*}{ F-statistics } \\
\hline & Disease & Sample size & Disease & Sample size & & & & \\
\hline 5 & $\begin{array}{l}\text { Myocardial } \\
\text { infarction }\end{array}$ & $\begin{array}{lr}\text { Total: } & 171,875 ; \\
\text { Cases: } & 43,676 ; \\
\text { Controls: } & 128,199\end{array}$ & Depression & $\begin{array}{l}\text { Total: } 500,199 ; \\
\text { Cases: } 170,756 ; \\
\text { Controls: } 329,443\end{array}$ & Primary analysis & $25(34-4-5)$ & 2.732 & 14050.26 \\
\hline 6 & $\begin{array}{l}\text { Atrial } \\
\text { fibrillation }\end{array}$ & $\begin{array}{lr}\text { Total: } & 1,030,836 \\
\text { Cases: } & 60,620 ; \\
\text { Controls: } & 970,216\end{array}$ & Depression & $\begin{array}{l}\text { Total: } 500,199 ; \\
\text { Cases: } 170,756 ; \\
\text { Controls: } 329,443\end{array}$ & Primary analysis & $149(166-10-7)$ & 5.625 & 29814.19 \\
\hline \multirow[t]{2}{*}{7} & \multirow{2}{*}{$\begin{array}{l}\text { Broad } \\
\text { depression }\end{array}$} & \multirow{2}{*}{$\begin{array}{l}\text { Total: } 322,580 ; \\
\text { Cases: } 113,769 ; \\
\text { Controls: } 208,811\end{array}$} & \multirow{2}{*}{$\begin{array}{l}\text { Coronary } \\
\text { artery disease }\end{array}$} & \multirow{2}{*}{$\begin{array}{l}\text { Total: } 184,305 ; \\
\text { Cases: } 60,801 ; \\
\text { Controls: } 123,504\end{array}$} & $\begin{array}{l}\text { Secondary } \\
\text { analysis }\end{array}$ & $10(14-1-3)$ & 0.009 & 17.59 \\
\hline & & & & & $\begin{array}{l}\text { Sensitivity } \\
\text { analysis }\end{array}$ & 9 & 0.008 & 15.75 \\
\hline \multirow{2}{*}{8} & \multirow{2}{*}{$\begin{array}{l}\text { Broad } \\
\text { depression }\end{array}$} & \multirow{2}{*}{$\begin{array}{l}\text { Total: } 322,580 ; \\
\text { Cases: } 113,769 ; \\
\text { Controls: } 208,811\end{array}$} & \multirow{2}{*}{$\begin{array}{l}\text { Myocardial } \\
\text { infarction }\end{array}$} & \multirow{2}{*}{$\begin{array}{l}\text { Total: } 171,875 ; \\
\text { Cases: } 43,676 ; \\
\text { Controls: } 128,199\end{array}$} & $\begin{array}{c}\text { Secondary } \\
\text { analysis }\end{array}$ & $10(14-1-3)$ & 0.009 & 16.47 \\
\hline & & & & & $\begin{array}{c}\text { Sensitivity } \\
\text { analysis }\end{array}$ & 9 & 0.008 & 14.75 \\
\hline \multirow{2}{*}{9} & \multirow{2}{*}{$\begin{array}{l}\text { Broad } \\
\text { depression }\end{array}$} & \multirow{2}{*}{$\begin{array}{l}\text { Total: } 322,580 ; \\
\text { Cases: } 113,769 ; \\
\text { Controls: } 208,811\end{array}$} & \multirow{2}{*}{$\begin{array}{l}\text { Atrial } \\
\text { fibrillation }\end{array}$} & \multirow{2}{*}{$\begin{array}{lr}\text { Total: } & 1,030,836 ; \\
\text { Cases: } & 60,620 ; \\
\text { Controls: } & 970,216\end{array}$} & $\begin{array}{l}\text { Secondary } \\
\text { analysis }\end{array}$ & $10(14-1-3)$ & 0.009 & 93.78 \\
\hline & & & & & $\begin{array}{l}\text { Sensitivity } \\
\text { analysis }\end{array}$ & 9 & 0.008 & 83.47 \\
\hline
\end{tabular}




\begin{tabular}{|c|c|c|c|c|c|c|c|c|}
\hline & \multicolumn{2}{|c|}{ Exposure } & \multicolumn{2}{|c|}{ Outcome } & \multirow{2}{*}{$\begin{array}{l}\text { Primary / } \\
\text { Secondary / } \\
\text { Sensitivity } \\
\text { analysis? }\end{array}$} & \multirow[b]{2}{*}{$\begin{array}{l}\text { Number of genetic } \\
\text { instruments included } \\
\text { in MR analysis } \\
\text { (Total number of } \\
\text { independent genetic } \\
\text { variants identified in } \\
\text { GWAS - number of } \\
\text { genetic variants } \\
\text { excluded due to lack of } \\
\text { proxies - number of } \\
\text { pleiotropic variants) }\end{array}$} & \multirow[b]{2}{*}{$\begin{array}{l}\text { Proportion } \\
\text { of variance } \\
\text { explained by } \\
\text { the genetic } \\
\text { instruments } \\
\text { on exposure } \\
\text { (\%) }\end{array}$} & \multirow[b]{2}{*}{ F-statistics } \\
\hline & Disease & Sample size & Disease & Sample size & & & & \\
\hline 10 & $\begin{array}{l}\text { Coronary artery } \\
\text { disease }\end{array}$ & $\begin{array}{l}\text { Total: } 184,305 ; \\
\text { Cases: } 60,801 ; \\
\text { Controls: } 123,504 \\
\end{array}$ & $\begin{array}{l}\text { Broad } \\
\text { depression }\end{array}$ & $\begin{array}{l}\text { Total: } 322,580 ; \\
\text { Cases: } 113,769 ; \\
\text { Controls: } 208,811 \\
\end{array}$ & $\begin{array}{l}\text { Secondary } \\
\text { analysis }\end{array}$ & $47(63-6-10)$ & 4.225 & 14231.23 \\
\hline 11 & $\begin{array}{l}\text { Myocardial } \\
\text { infarction }\end{array}$ & $\begin{array}{l}\text { Total: } 171,875 \\
\text { Cases: } 43,676 ; \\
\text { Controls: } 128,199\end{array}$ & $\begin{array}{l}\text { Broad } \\
\text { depression }\end{array}$ & $\begin{array}{l}\text { Total: } 322,580 ; \\
\text { Cases: } 113,769 ; \\
\text { Controls: } 208,811\end{array}$ & $\begin{array}{l}\text { Secondary } \\
\text { analysis }\end{array}$ & $25(34-4-5)$ & 2.674 & 8863.78 \\
\hline 12 & $\begin{array}{l}\text { Atrial } \\
\text { fibrillation }\end{array}$ & $\begin{array}{lr}\text { Total: } & 1,030,836 \\
\text { Cases: } & 60,620 \\
\text { Controls: } 970,216\end{array}$ & $\begin{array}{l}\text { Broad } \\
\text { depression }\end{array}$ & $\begin{array}{l}\text { Total: } 322,580 ; \\
\text { Cases: } 113,769 ; \\
\text { Controls: } 208,811\end{array}$ & $\begin{array}{l}\text { Secondary } \\
\text { analysis }\end{array}$ & $152(166-6-8)$ & 5.721 & 19575.67 \\
\hline
\end{tabular}


Table 2. Genetic correlation among the two depression phenotypes and various CVD

\begin{tabular}{|c|c|c|c|c|}
\hline & Trait 1 & Trait 2 & Genetic correlation r (Standard Error) & P-value \\
\hline 1 & Depression & Broad depression & $0.9732(0.0041)$ & 0 \\
\hline 2 & Depression & Coronary artery disease & $0.1328(0.0244) \#$ & $5.44 \times 10^{-8} \#$ \\
\hline 3 & Depression & Myocardial infarction & $0.1688(0.0294)$ & $9.03 \times 10^{-9}$ \\
\hline 4 & Depression & Stroke & $0.0715(0.0414)$ & 0.08 \\
\hline 5 & Depression & Atrial fibrillation & $0.1124(0.0251)$ & $7.80 \times 10^{-6}$ \\
\hline 6 & Broad depression & Coronary artery disease & $0.1236(0.0288) \#$ & $1.71 \times 10^{-5} \#$ \\
\hline 7 & Broad depression & Myocardial infarction & $0.1231(0.0324)$ & $1 \times 10^{-4}$ \\
\hline 8 & Broad depression & Stroke & $0.0674(0.0434)$ & 0.1204 \\
\hline 9 & Broad depression & Atrial fibrillation & $0.1258(0.0272)$ & $3.62 \times 10^{-6}$ \\
\hline
\end{tabular}

\# Genetic correlation between the two depression phenotypes and coronary artery disease were computed in the original GWAS (Howard et al., 2018) / GWAS meta-analysis (Howard et al., 2019). The relevant figures were extracted here. 


\section{References}

Ahola-Olli, A. V., Wurtz, P., Havulinna, A. S., Aalto, K., Pitkanen, N., Lehtimaki, T., .. . Raitakari, O. T. (2017). Genome-wide Association Study Identifies 27 Loci Influencing Concentrations of Circulating Cytokines and Growth Factors. American Journal of Human Genetics, 100, 40-50. doi: 10.1016/j.ajhg.2016.11.007.

Ambrose, J. A. \& Barua, R. S. (2004). The pathophysiology of cigarette smoking and cardiovascular disease: an update. Journal of the American College of Cardiology, 43, 1731-7. doi: 10.1016/j.jacc.2003.12.047.

Atlantis, E., Lange, K., Goldney, R. D., Martin, S., Haren, M. T., Taylor, A., . . . Wittert, G. A. (2011). Specific medical conditions associated with clinically significant depressive symptoms in men. Social Psychiatry and Psychiatric Epidemiology, 46, 1303-12. doi: 10.1007/s00127-010-0302-3.

Bacon, S. L. (2019). Stress, psychiatric disorders, and cardiovascular disease. $B M J, 365$, 11577. doi: 10.1136/bmj.11577.

Barlinn, K., Kepplinger, J., Puetz, V., Illigens, B. M., Bodechtel, U. \& Siepmann, T. (2015). Exploring the risk-factor association between depression and incident stroke: a systematic review and meta-analysis. Neuropsychiatric Disease and Treatment, 11, 1-14. doi: $10.2147 /$ NDT.S63904.

Berkman, L. F., Blumenthal, J., Burg, M., Carney, R. M., Catellier, D., Cowan, M. J., . . Enhancing Recovery in Coronary Heart Disease Patients, I. (2003). Effects of treating depression and low perceived social support on clinical events after myocardial infarction: the Enhancing Recovery in Coronary Heart Disease Patients (ENRICHD) Randomized Trial. JAMA, 289, 3106-16. doi: 10.1001/jama.289.23.3106.

Bowden, J., Davey Smith, G. \& Burgess, S. (2015). Mendelian randomization with invalid instruments: effect estimation and bias detection through Egger regression. International Journal of Epidemiology, 44, 512-25. doi: 10.1093/ije/dyv080.

Bowden, J., Davey Smith, G., Haycock, P. C. \& Burgess, S. (2016). Consistent Estimation in Mendelian Randomization with Some Invalid Instruments Using a Weighted Median Estimator. Genetic Epidemiology, 40, 304-14. doi: 10.1002/gepi.21965.

Brion, M. J., Shakhbazov, K. \& Visscher, P. M. (2013). Calculating statistical power in Mendelian randomization studies. International Journal of Epidemiology, 42, 1497-501. doi: $10.1093 / \mathrm{ije} /$ dyt179.

Bulik-Sullivan, B., Finucane, H. K., Anttila, V., Gusev, A., Day, F. R., Loh, P. R., . . Neale, B. M. (2015a). An atlas of genetic correlations across human diseases and traits. Nature Genetics, 47, 1236-41. doi: 10.1038/ng.3406.

Bulik-Sullivan, B. K., Loh, P. R., Finucane, H. K., Ripke, S., Yang, J., Schizophrenia Working Group of the Psychiatric Genomics, C., . . Neale, B. M. (2015b). LD Score regression distinguishes confounding from polygenicity in genome-wide association studies. Nature Genetics, 47, 291-5. doi: 10.1038/ng.3211.

Burgess, S., Butterworth, A. \& Thompson, S. G. (2013). Mendelian randomization analysis with multiple genetic variants using summarized data. Genetic Epidemiology, 37, 658-65. doi: 10.1002/gepi.21758.

Burgess, S., Davies, N. M. \& Thompson, S. G. (2016). Bias due to participant overlap in two-sample Mendelian randomization. Genetic Epidemiology, 40, 597-608. doi: 10.1002/gepi.21998. 
Burgess, S. \& Labrecque, J. A. (2018). Mendelian randomization with a binary exposure variable: interpretation and presentation of causal estimates. European Journal of Epidemiology, 33, 947-952. doi: 10.1007/s10654-018-0424-6.

Burgess, S., Thompson, D. J., Rees, J. M. B., Day, F. R., Perry, J. R. \& Ong, K. K. (2017). Dissecting Causal Pathways Using Mendelian Randomization with Summarized Genetic Data: Application to Age at Menarche and Risk of Breast Cancer. Genetics, 207, 481-487. doi: 10.1534/genetics.117.300191.

Burgess, S. \& Thompson, S. G. (2015). Multivariable Mendelian randomization: the use of pleiotropic genetic variants to estimate causal effects. American Journal of Epidemiology, 181, 251-60. doi: 10.1093/aje/kwu283.

Carney, R. M. \& Freedland, K. E. (2017). Depression and coronary heart disease. Nature Reviews Cardiology, 14, 145-155. doi: 10.1038/nrcardio.2016.181.

Davies, N. M., Holmes, M. V. \& Davey Smith, G. (2018). Reading Mendelian randomisation studies: a guide, glossary, and checklist for clinicians. $B M J, 362$, k601. doi: 10.1136/bmj.k601.

Emdin, C. A., Odutayo, A., Wong, C. X., Tran, J., Hsiao, A. J. \& Hunn, B. H. (2016). Meta-Analysis of Anxiety as a Risk Factor for Cardiovascular Disease. The American Journal of Cardiology, 118, 511-9. doi: 10.1016/j.amjcard.2016.05.041.

Enko, D., Brandmayr, W., Halwachs-Baumann, G., Schnedl, W. J., Meinitzer, A. \& Kriegshauser, G. (2018). Prospective plasma lipid profiling in individuals with and without depression. Lipids in Health and Disease, 17, 149. doi: 10.1186/s12944-0180796-3.

Gafoor, R., Booth, H. P. \& Gulliford, M. C. (2018). Antidepressant utilisation and incidence of weight gain during 10 years' follow-up: population based cohort study. $B M J$, 361, k1951. doi: 10.1136/bmj.k1951.

Galling, B., Roldan, A., Nielsen, R. E., Nielsen, J., Gerhard, T., Carbon, M., . . . Correll, C. U. (2016). Type 2 Diabetes Mellitus in Youth Exposed to Antipsychotics: A Systematic Review and Meta-analysis. JAMA Psychiatry, 73, 247-59. doi: 10.1001/jamapsychiatry.2015.2923.

Gan, Y., Gong, Y., Tong, X., Sun, H., Cong, Y., Dong, X., . . . Lu, Z. (2014). Depression and the risk of coronary heart disease: a meta-analysis of prospective cohort studies. $B M C$ Psychiatry, 14, 371. doi: 10.1186/s12888-014-0371-z.

Garg, P. K., O'Neal, W. T., Diez-Roux, A. V., Alonso, A., Soliman, E. Z. \& Heckbert, S. (2019). Negative Affect and Risk of Atrial Fibrillation: MESA. Journal of the American Heart Association, 8, e010603. doi: 10.1161/JAHA.118.010603.

GBD 2017 Disease and Injury Incidence and Prevalence Collaborators (2018). Global, regional, and national incidence, prevalence, and years lived with disability for 354 diseases and injuries for 195 countries and territories, 1990-2017: a systematic analysis for the Global Burden of Disease Study 2017. Lancet, 392, 1789-1858. doi: 10.1016/S0140-6736(18)32279-7.

Gill, D., James, N. E., Monori, G., Lorentzen, E., Fernandez-Cadenas, I., Lemmens, R., . . the, G. N. (2019). Genetically Determined Risk of Depression and Functional Outcome After Ischemic Stroke. Stroke, 50, 2219-2222. doi: 10.1161/STROKEAHA.119.026089. Girardin, F. R., Gex-Fabry, M., Berney, P., Shah, D., Gaspoz, J. M. \& Dayer, P. (2013). Drug-induced long QT in adult psychiatric inpatients: the 5-year cross-sectional ECG Screening Outcome in Psychiatry study. The American Journal of Psychiatry, 170, 146876. doi: 10.1176/appi.ajp.2013.12060860. 
Goren, A., Liu, X., Gupta, S., Simon, T. A. \& Phatak, H. (2013). Quality of life, activity impairment, and healthcare resource utilization associated with atrial fibrillation in the US National Health and Wellness Survey. PLoS One, 8, e71264. doi: 10.1371/journal.pone.0071264.

Hartwig, F. P., Davies, N. M., Hemani, G. \& Davey Smith, G. (2016). Two-sample Mendelian randomization: avoiding the downsides of a powerful, widely applicable but potentially fallible technique. International Journal of Epidemiology, 45, 1717-1726. doi: 10.1093/ije/dyx028.

Hoffmann, T. J., Ehret, G. B., Nandakumar, P., Ranatunga, D., Schaefer, C., Kwok, P. Y., . . . Risch, N. (2017). Genome-wide association analyses using electronic health records identify new loci influencing blood pressure variation. Nature Genetics, 49, 5464. doi: $10.1038 / \mathrm{ng} .3715$.

Howard, D. M., Adams, M. J., Clarke, T. K., Hafferty, J. D., Gibson, J., Shirali, M., . . McIntosh, A. M. (2019). Genome-wide meta-analysis of depression identifies 102 independent variants and highlights the importance of the prefrontal brain regions. Nature Neuroscience, 22, 343-352. doi: 10.1038/s41593-018-0326-7.

Howard, D. M., Adams, M. J., Shirali, M., Clarke, T. K., Marioni, R. E., Davies, G., . . McIntosh, A. M. (2018). Genome-wide association study of depression phenotypes in UK Biobank identifies variants in excitatory synaptic pathways. Nature Communications, 9, 1470. doi: 10.1038/s41467-018-03819-3.

Howren, M. B., Lamkin, D. M. \& Suls, J. (2009). Associations of depression with Creactive protein, IL-1, and IL-6: a meta-analysis. Psychosomatic Medicine, 71, 171-86. doi: 10.1097/PSY.0b013e3181907c1b.

Hyde, C. L., Nagle, M. W., Tian, C., Chen, X., Paciga, S. A., Wendland, J. R., . . . Winslow, A. R. (2016). Identification of 15 genetic loci associated with risk of major depression in individuals of European descent. Nature Genetics, 48, 1031-6. doi: 10.1038/ng.3623.

Jostins, L. (2017). Mangrove: Risk prediction on trees. https://cran.rproject.org/web/packages/Mangrove/index.html.

Kamphuis, M. H., Geerlings, M. I., Tijhuis, M. A., Giampaoli, S., Nissinen, A., Grobbee, D. E. \& Kromhout, D. (2007). Physical inactivity, depression, and risk of cardiovascular mortality. Medicine \& Science in Sports \& Exercise, 39, 1693-9. doi: 10.1249/mss.0b013e3180f6109f.

Kannel, W. B. \& McGee, D. L. (1979). Diabetes and cardiovascular disease. The Framingham study. JAMA, 241, 2035-8. doi: 10.1001/jama.241.19.2035.

Khan, S. S., Ning, H., Wilkins, J. T., Allen, N., Carnethon, M., Berry, J. D., . . . LloydJones, D. M. (2018). Association of Body Mass Index With Lifetime Risk of Cardiovascular Disease and Compression of Morbidity. JAMA Cardiology, 3, 280-287. doi: 10.1001/jamacardio.2018.0022.

Larsson, S. C. \& Markus, H. S. (2019). Genetic Liability to Insomnia and Cardiovascular Disease Risk. Circulation, 140, 796-798. doi: 10.1161/CIRCULATIONAHA.119.041830.

Lawlor, D. A. (2016). Commentary: Two-sample Mendelian randomization: opportunities and challenges. International Journal of Epidemiology, 45, 908-15. doi: 10.1093/ije/dyw127.

Lewington, S., Clarke, R., Qizilbash, N., Peto, R., Collins, R. \& Prospective Studies, C. (2002). Age-specific relevance of usual blood pressure to vascular mortality: a meta- 
analysis of individual data for one million adults in 61 prospective studies. Lancet, 360, 1903-13. doi: 10.1016/s0140-6736(02)11911-8.

Libby, P. (2006). Inflammation and cardiovascular disease mechanisms. The American Journal of Clinical Nutrition, 83, 456S-460S. doi: 10.1093/ajen/83.2.456S.

Lippi, G., Montagnana, M., Favaloro, E. J. \& Franchini, M. (2009). Mental depression and cardiovascular disease: a multifaceted, bidirectional association. Seminars in Thrombosis and Hemostasis, 35, 325-36. doi: 10.1055/s-0029-1222611.

Luppino, F. S., de Wit, L. M., Bouvy, P. F., Stijnen, T., Cuijpers, P., Penninx, B. W. \& Zitman, F. G. (2010). Overweight, obesity, and depression: a systematic review and metaanalysis of longitudinal studies. Archives Of General Psychiatry, 67, 220-9. doi: 10.1001/archgenpsychiatry.2010.2.

Nikpay, M., Goel, A., Won, H. H., Hall, L. M., Willenborg, C., Kanoni, S., . . Farrall, M. (2015). A comprehensive 1,000 Genomes-based genome-wide association metaanalysis of coronary artery disease. Nature Genetics, 47, 1121-1130. doi: 10.1038/ng.3396.

Nutt, D., Wilson, S. \& Paterson, L. (2008). Sleep disorders as core symptoms of depression. Dialogues in Clinical Neuroscience, 10, 329-36. doi.

Parekh, A., Smeeth, D., Milner, Y. \& Thure, S. (2017). The Role of Lipid Biomarkers in Major Depression. Healthcare (Basel), 5. doi: 10.3390/healthcare5010005.

Pepys, M. B. \& Hirschfield, G. M. (2003). C-reactive protein: a critical update. Journal of Clinical Investigation, 111, 1805-12. doi: 10.1172/JCI18921.

Pierce, B. L. \& Burgess, S. (2013). Efficient design for Mendelian randomization studies: subsample and 2-sample instrumental variable estimators. American Journal of Epidemiology, 178, 1177-84. doi: 10.1093/aje/kwt084.

Prins, B. P., Kuchenbaecker, K. B., Bao, Y., Smart, M., Zabaneh, D., Fatemifar, G., . . . Zeggini, E. (2017). Genome-wide analysis of health-related biomarkers in the UK Household Longitudinal Study reveals novel associations. Scientific Reports, 7, 11008. doi: 10.1038/s41598-017-10812-1.

Rees, J. M. B., Wood, A. M. \& Burgess, S. (2017). Extending the MR-Egger method for multivariable Mendelian randomization to correct for both measured and unmeasured pleiotropy. Statistics in Medicine, 36, 4705-4718. doi: 10.1002/sim.7492.

Shapiro, P. A. (2013). Depression treatment and coronary artery disease outcomes: time for reflection. Journal of Psychosomatic Research, 74, 4-5. doi: 10.1016/j.jpsychores.2012.11.008.

Song, H., Fang, F., Arnberg, F. K., Mataix-Cols, D., Fernandez de la Cruz, L., Almqvist, C., ... Valdimarsdottir, U. A. (2019). Stress related disorders and risk of cardiovascular disease: population based, sibling controlled cohort study. BMJ, 365, 11255. doi: 10.1136/bmj.11255.

Sparrenberger, F., Cichelero, F. T., Ascoli, A. M., Fonseca, F. P., Weiss, G., Berwanger, O., . . . Fuchs, F. D. (2009). Does psychosocial stress cause hypertension? A systematic review of observational studies. Journal of Human Hypertension, 23, 12-9. doi: 10.1038/jhh.2008.74.

Staley, J. R., Blackshaw, J., Kamat, M. A., Ellis, S., Surendran, P., Sun, B. B., . . . Butterworth, A. S. (2016). PhenoScanner: a database of human genotype-phenotype associations. Bioinformatics, 32, 3207-3209. doi: 10.1093/bioinformatics/btw373.

Vancampfort, D., Mitchell, A. J., De Hert, M., Sienaert, P., Probst, M., Buys, R. \& Stubbs, B. (2015). Type 2 Diabetes in Patients with Major Depressive Disorder: A Meta-Analysis 
of Prevalence Estimates and Predictors. Depression and Anxiety, 32, 763-73. doi: 10.1002/da.22387.

Verbanck, M., Chen, C. Y., Neale, B. \& Do, R. (2018). Detection of widespread horizontal pleiotropy in causal relationships inferred from Mendelian randomization between complex traits and diseases. Nature Genetics, 50, 693-698. doi: 10.1038/s41588-018-0099-7.

Welty, F. K. (2013). How do elevated triglycerides and low HDL-cholesterol affect inflammation and atherothrombosis? Current Cardiology Reports, 15, 400. doi: 10.1007/s11886-013-0400-4.

Wootton, R. E., Richmond, R. C., Stuijfzand, B. G., Lawn, R. B., Sallis, H. M., Taylor, G. M. J., . . . Munafò, M. R. (2018). Causal effects of lifetime smoking on risk for depression and schizophrenia: Evidence from a Mendelian randomisation study bioRxiv. doi.

World Health Organization (2017). "Depression: let's talk" says WHO, as depression tops list of causes of ill health. pp. News Release: https://www.who.int/news-room/detail/3003-2017--depression-let-s-talk-says-who-as-depression-tops-list-of-causes-of-ill-health.

Wray, N. R., Ripke, S., Mattheisen, M., Trzaskowski, M., Byrne, E. M., Abdellaoui, A., ... Major Depressive Disorder Working Group of the Psychiatric Genomics, C. (2018). Genome-wide association analyses identify 44 risk variants and refine the genetic architecture of major depression. Nature Genetics, 50, 668-681. doi: 10.1038/s41588018-0090-3.

Zuidersma, M., Conradi, H. J., van Melle, J. P., Ormel, J. \& de Jonge, P. (2013). Depression treatment after myocardial infarction and long-term risk of subsequent cardiovascular events and mortality: a randomized controlled trial. Journal of Psychosomatic Research, 74, 25-30. doi: 10.1016/j.jpsychores.2012.08.015. 